\title{
Dios, ¿principio de necesidad o interpelación absoluta a la libertad?
}

\author{
Análisis del concepto de Dios-necesidad \\ en la tradición filosófica griega.
}

\section{Josep Vives, \\ Centro Borja, Sant Cugat del Vallés, Barcelona.}

Es habitual concebir la teología de la liberación como una forma de reflexión crítica sobre la praxis cristiana desde la misma praxis y a la luz de la palabra de Dios. Es una rẹlexión que tiene, pues, como tema preferente de atención el obrar humano como respuesta responsable - si se me tolera la redundancia - al designio de Dios sobre el mundo y la historia. Ocasionalmente los teólogos de la liberación se han puesto a considerar que el en[oque teológico que adoptan con voluntad de fidelidad a la tradición bíblica supone una determinada concepción del ser mismo de Dios, que no puede darse simplemente por supuesta. El Dios que se presupone en la teología de la liberación, en lidelidad a la tradición bibilica, no es simplemente el Dios "ser-necesario," mero fundamento absoluto y necesario de cuanto existe, que había sido objeto primario de atención de la llamada "ontotcología" clásica armada con el instrumental de una melafísica de cuño aristotélicoLmista. El Dios bíblico al que retoma la teología de la liberación es, ante todo, el Dios libre y principio de libertad, amoroso creador de la libertad humana y de la historia, que con ello se constituye en promotor y garante del valor y dcl sentido de la misma historia, y en interpelación absoluta para el hombre a quien conffa la realización concrela de esta historia. Esta concepción de Dios, que me parece el punto nuclear de la teología de la liberación, fue objeto de un primer análisis en mi aportación —itulada "El ídolo y la voz" - a la obra colectiva $L a$ justicia que brota de la fe. ${ }^{1}$ En este trabajo ofrezco un análisis complementario - a modo de fondo de contraste- acerca de la noción de Dios prevalente en la tradición filosófica griega. Mi interés principal se ha dirigido a detectar los elementos que configuran aquella tradición filosófica, sin detenerme explícitamente en contraponerlos a los elementos diferenciales de la tradición biblico-cristiana. 
El contraste resultará explícito a parir de mi trabajo anterior, por lo demás, será obvio a cualquiera mínimamente informado del actual estado de la teología.

Nos ofrece un buen punto de partida la tesis del ilustre filólogo clásico y humanista cristiano Werner Jaeger, en su muy estimable obra Teología de los primeros filósofos griegos. ${ }^{2}$ La tradición liberal-historicista había presentado la evolución del pensamiento filosofico griego como un proceso lineal de progresiva racionalización y "secularización," como una cada vez más fuerte afirmación de la racionalidad pura frente a los esquemas arcaicos de interpretación del mundo, de mentalidad mítico-religiosa. ${ }^{3}$ Ulteriormente, historiadores más perspicaces, como el profesor de Oxford E. R. Dodds, pudieron hacer notar que el proceso de racionalización en Grecia no había sido ni tan lineal ni tan profundo como se había pensado. ${ }^{4}$ Finalmente, W. Jaeger, en la obra cilada, defendía que en la evolución del pensamiento griego se da cierlamente un movimiento racionalizador, pero que tal movimiento no es propiamente arreligioso y secularizador, en forma de pura superación y substitución de lo mítico-religioso, sino que se da más bien una profundización y reafirmación de lo que ya el milo quería significar en forma de develamiento del auténtico principio divino de la naturaleza, más allá de las figuras imaginativas y arcaicas de los dioses de la milologfa.

Esta perspectiva de Jaeger resulta ciertamente interesante, y nadie negará que el autor, con su vastísima erudición, no haga resaltar aspectos muy importantes del pensamiento griego. Pero quizás habríamos de decir que se trata de una perspectiva verdadera, pero unilateral; que el pensamiento filosólico de Grecia no queda adecuadamente caracterizado ni como una superación, ni como una profundización de la religión o del mito por la racionalidad positiva.

Por mi parte no pretendo presentar ninguna nueva interpretación más profunda - más global. Quisiera hacer unas pocas observaciones sobre el papel que el concepto de necesidad tuvo en el pensamiento de los griegos y sobre la manera cómo, a partir de este conceplo, podríamos intentar opinar sobre el carácter religioso o secular de la filosofía griega, y sobre la inlluencia que esta filosofia ha tenido, indudablemente, en la teología cristiana.

\section{El mundo entre el capricho de los dioses $y$ la necesidad de la na- turaleza: la ciencia jónica}

Se ha entendido la ciencia jónica como un intento de comprensión de la realidad múltiple a partir de un principio o arje unitaria. Lo que aparece como múltiple en realidad es uno, o al menos procede de un principio único. En el trasfondo de los filosofos jónicos hay un conjunto de presupuestos implícilos: la multiplicidad puede y debe ser entendida como unidad; la apariencia de las cosas se puede y debe reducir a una realidad ulterior y no inmediatamente aparente; la contingencia o imprevisibilidad de los múltiples acontecimientos y fenómenos puede ser reducida a un principio de necesidad. La ciencia modema sigue viviendo de estos presupuestos. 
Para Tales y para el hombre moderno, conocer una cosa quiere decir establecer la relación necesaria de sus múltiples manifestaciones con un principio unitario y superior de explicación. Los variados y múltiples fenómenos de la experiencia se explican por referencia a unos pocos principios o elementos (físicos, químicos, matemáticos,...), en virtud de unas "leyes" necesarias de causalidad, de estructura, de atracción-repulsión, de interferencia... Se postula un principio o, al menos, unos pocos principios necesarios: agua, aire, apeiron, elementos, átomos, partículas..., de los que deriva necesariamente toda la multiplicidad de seres y fenomenos contingentes. Desde Tales, conocer científicamente ha consistido en reducir la multiplicidad y contingencia a unidad y necesidad (al menos, parciales y relativas).

Pienso que por aqul vamos a dar con uno de los elementos esenciales de la distinción tradicional entre pensamiento mítico y pensamiento racional: el pensamiento mítico intenta explicar la multiplicidad contingente por referencia a unos principios de libertad: la voluntad o el capricho de los dioses. El pensamiento racional intenta explicar la misma multiplicidad por unos principios de necesidad: arje, fysis, lo que se llamara la "ley natural." Se ha subrayado muchas veces la proximidad que hay entre la idea de Tales "todo es agua" y la idea de Homero, cuando dice que "el Oceano es padre de todas las cosas" (Illiada XIV, 201, 246). Aristoteles en la Metofisica (A. 983 b 21) ya vio esta afinidad. Tanto Homero como Tales quieren explicar la multiplicidad en relación a una categoría de causalidad. Pero, para Homero, se concibe la causa de todo en coordenadas míticas, es decir, la causa es imaginada antropomórficamente y actúa de manera antropomórfica. En cambio, Tales habla ya de una causa concebida abstractamente - "el agua" - que actía en virtud de unos principios intrínsecos y necesarios de la misma naturaleza de las cosas.

El mito intenta descubrir unidad en la multiplicidad no por referencia a un principio constitutivo e intrínseco, concebido abstractamente, sino por referencia a un agente que actúa en el tiempo y en el espacio. El mito habla de los inicios, del comienzo de las cosas: consiruye "cosmogonias," no precisamente "cosmologfas." El primer modelo de explicación de la realidad es el de la causa eficiente: quién ha hecho las cosas. Es una paradigma antropomórfico, que nace de la experiencia del homo faber. La realidad todavia no se comprende abstractamente como "ser," sino como "hacerse," y por eso el mito se expresa en relalos, en historias, que quieren explicar cómo unos agentes muy superiores al hombre son causa de lodo lo que sucede, aunque aquéllos sólo pueden ser concebidos como actuando antropomórficamente - con voluntad libre.

El pensamiento racional, en cambio, intenta explicar el devenir por un principio intrínseco de necesidad, concebido abstractamente. La misión de la ciencia es precisamente la de reducir el devenir aparentemente cático y contingente a algo estable, necesario: busca las "leyes" constantes, universales, inmutables (al menos, relativamente) del devenir; busca cómo son las constantes universales del devenir, más allá del espacio y del tiempo. Reduce el devenir al "ser". Por esto la 
ciencia ya no cuenta relatos o historias, sino que emite cnunciados con pretensión de validez universal y atemporal (al menos, relativa, dentro de un ámbito determinado). Aristóteles ya dejó establecido que la ciencia se expresa en proposiciones universales y necesarias, y las primeras proposiciones formalmente "científicas" fueron las de aquellos pensadores de Jonia, que dijeron que "todo es agua," o "aire", o "apeiron."

Desde entonces es científico todo lo que puede ser determinado y relacionado con necesidad. Lo gratuito, lo imprevisible, lo que sólo sucede por azar, ni es científico ni racional. Cierto que hay realidades y acontecimientos, cuyos condicionamientos necesarios aún no se conocen y quizás nunca puedan serlo. Estas realidades, al no ser aún conocidas cientílicamente, son para nosotros objeto del azar. Pero en realidad el espíitu racional presupone una necesidad universal correlativa a una inteligibilidad universal de todo. Lo absolutamente gratuito y casual, es decir, no sometido a relaciones necesarias de ningún tipo, sería algo absolutamente ininteligible, irracional: desde los presupuestos del espíritu racional, sencillamente no podría existir. Es esto lo que más adelante será formulado en el principio "lodo tiene una razón necesaria y suficiente," que es la base del pensar racional y presupuesio de toda actividad científica. Esta consiste precisamente en descubrir, relacionar y sistematizar las razones necesarias de wodas las cosas.

Evidentemente, de ninguna manera quiero sugerir que esto lo hayan razonado así los pensadores de Jonia. Pero éste era el movimiento implícito en su actitud mental ante el mundo, y tal vez no sólo implícito. Quizás no hay mucha probabilidad de que Tales haya pronunciado en realidad la sentencia que le atribuye Diógenes Laercio (1,35: DK 11 A 1): "Nada hay más fuerte que la necesidad: ella lo domina todo." Pero muy probablemente el texto filosófico griego más antiguo que poseemos es el que Simplicio atribuye a Anaximandro (DK 12 B 1). Y en este lexto sí se nos habla ya de una unidad subyacente a un proceso general de generación y de corrupción, que tiene lugar según un principio de necesidad (kata to jreon). Y lo explica inmediatamente, todavía en términos míticos, como una restitución judicial de aquello que en ese proceso unas cosas "roban" a otras, "según el orden del tiempo." Es decir, Anaximandro intenta comprender la realidad como un proceso, en el fondo, unitario y necesario. Esto es lo que desde entonces ha pretendido hacer toda la ciencia racional.

\section{EI pensar y el ser: necesidad lógica y necesidad ontólógica}

El presupuesto epistemológico del pensamiento racional es el de la equivalencia entre realidad y verdad. Conocer es lograr una adaequatio mentis ad rem. Cuando se consigue esto, la realidad se conoce tal como es y es tal como se conoce. Parménides lo estableció como base de su especulación: "Es lo mismo el pensar y el ser." Evidentemente los aniguos tenían conciencia de que esta adaequatio no siempre se alcanza: pero entonces se est́́ en la opinión o en el error. Conocer es captar la realidad tal como es en sí. 
La tendencia a identificar el pensar y el ser lleva inevitablemente a identificar la necesidad lógica y la necesidad ontológica: es verdadero y necesario lo que ha de ser pensado necesariamente, y no puede ser lo que necesariamente (según las leyes del propio pensamiento) no puede ser pensado.. Las leyes necesarias del pensamiento (que fundamentalmente serían lo que se llamarán principios de no-contradicción, de tercio excluso y de razón suficiente, y todo lo que después seria concocido como categor(as a priori) son leyes necesarias de la realidad. Parménidis fue el primero en aplicar rigurosamente estos principios: sólo el ser es y puede ser pensado; el no-ser ni es ni puede ser pensado; no puede haber cambio o mutación, o multiplicidad, que supondrían el no-ser. Solamente se puede admitir la existencia de la realidad total y necesaria.

Este principio de correlación $-e$ incluso de identidad-entre necesidad lógica y necesidad ontológica quedará como algo asumido básicamente por el pensamiento griego posterior. Conocer, poseer la verdad sobre la realidad, será afirmar una necesidad ontológica en virtud de una necesidad lógica, percibida según unas categorias de necesidad, que se expresaban en los llamados primeros principios. Dicho de otra manera, los primeros principios eran principios necesarios tanto del pensar como del ser. Por eso, su autonecesidad intrínseca -lógica y ontológica- es el único atributo propio de la realidad: el ser y lo necesario son lo mismo. En ningún lugar an bien expresado como en el fragmento 8,29-38 de Parménidis:

Lo mismo permanece en sí mismo, volviéndose sobre sí mismo y así es como permanece inmutable en un mismo lugar. La poderosa necesidad lo retiene con las cadenas que son su limite, y lo abarca por todos lados. Por eso no es admisible que lo que es sea indeterminado, ya que no le falta nada, mientras que si no luera estaría falto de todo. $Y$ asl, es lo mismo el pensar y el objeto del pensamiento, porque - fuera de lo que es- no encontrarás allá el pensamiento, que es su expresión. Porque nada existe ni existirá fuera de lo que es (ser), ya que la Moira lo encadenó para que fuera compacto e inmóvil...

El eleatismo representa una forma particularmente radical de afirmación del principio de necesidad como principio a la vez del ser y del conocer. Pero lo más notable es que, siendo esta afirmación tan excesiva y tan incongruente con la experiencia ordinaria de multiplicidad y de mutación, uviese tanta influencia en todo el pensamiento posterior. Porque todos los sistemas que vendrán después, incluidos los sistemas de Platón, de Aristóteles y de Plotino, de lodos se puede decir en verdad que son puros intentos para lograr que la experiencia de la realidad quepa dentro de los moldes epistemo-ontológicos del eleatismo, quizás forzando y deformando estos mismos moldes, pero nunca simplemente reventándolos o dejándolos de lado. El pensamiento griego nunca fue más que un eleatismo cualificado o un eleatismo aguado, porque en defínitiva no tiene más principio lógicoontológico que el de la necesidad. 


\section{Los eleatismos cuslificados o desleidos}

Quizás alguien replique que seguramente Heráclito se podría librar de eca afimación tan inconsideradamente generalizadora. Creo que no del todo. Pienso que Heráclito, quien siempre ha sido considerado como el anti-Parmenides (prescindiendo de la dificil cuestión de las relaciones históricas e ideológicas que haya podido haber entre los dos), es por eso mismo muy "parmenidiano." Todos los "antis" suelen ser lo mismo que sus oponentes, solo que en el extremo opuesto: "los extremos se tocan," que viene a ser nuestra versión del dicho de Heráclito: "el principio y el fin son lo mismo" (DK 22 B 103). Quiero decir que formalmente no parece haber diferencia alguna entre un sistema basado en la necesidad lógico-ontológica de un devenir absoluto. Por esto mismo, porque es absolut y necesario, es un devenir paradojicamente inmutable, es decir, totalmente determinado y necesario, y por ello sujeto a un logos firme y determinado. Y me parece que las inacabables discusiones de los estudiosos sobre si el logos de Heráclito es primariamente un logos objetivo (la ley constitutiva de la realidad) o un logos subjetivo (la ley de nuestra aprehensión de la realidad) expresan el problema paralelo al de Parménides sobre el pensar y el ser, de manera que no puede haber otra solución que la de afirnar "parmenidianamente" la identidad total del logos subjetivo y del objetivo, paralela a la identidad entre el pensar y el ser. También en Heráclito sólo hay lugar para la necesidad, aunque aqui sea la necesidad del dinamismo y del movimientn: "todo sucede de acuerdo con la lucha y la necesidad" (DK 22 B 80; cf. A 1). Y por esto sólo se puede concebir este movimiento como un movimiento circular y de retomo sobre si mismo. Aristóteles ya observó que únicamente en el movimiento circular se encuentra el movimiento absolutamente necesario, determinado y perfecto. Por eso, éste es el movimiento de las realidades celestes y divinas.

Pasemos a los sistemas que he calificado de eleatismos desleidos. El sistema de Empédocles se puede interpretar como un eleatismo cuarteado. La realidad tiene cuatro formas fundamentales, necesarias e inmutables - como el mismo ser de Parménides-, que se combinan con las fuerzas necesarias del amor y del odio, y dan lugar a las múluiples apariencias de los seres de nuestra experiencia ordinaria. Los atomistas presentan un eleatismo, que podrímos definir como desmenuzado: cada uno de los infinitos átomos tiene ahora las cualidades del ser de Parménides. Son átomos eternos, necesarios, indivisibles, inmutables, que se mueven con un movimiento intrínseco y necesario: únicamente su combinación fortuita produce la multiplicidad de los seres de nuestra experiencia. Y notemos aquí cómo la casualidad es sólo el reverso de la necesidad propia de los mismos átomos y de su movimiento.

El pensamiento de Anaxágoras es más sutil y, además, mal conocido, dada la forma fragmentaria en que nos ha llegado. Por una parte, parece que su teorla de las "homeomerías" sería únicamente una versión mucho más sutil y fexible de la vieja teoría de los elementos: tal vez como una especie de atomismo cualitativo; quiero decir un atomismo con átomos diferenciados cualitativamente, y no sólo 
en forma y figura, como los de Demórito. Por otra parte, al introducir el Nous o inteligencia como principio, parecfa introducir por primera vez en la filosofia natural griega un elemento de finalidad y de libertad. Pero lodos sabemos cómo el Sócrates platónico se lamentaba de que Anaxágoras en realidad no pudo liberarse de una concepción necesaria y mecanicista en su modo de ver la acción de la inteligencia El Nous, parece, permanecerfa dentro del marco de la necesidad.

En todos estos sistemas, se concibe el universo como una totalidad necesaria, vinculada a una necesidad a la vez lógica y ontológica. Conocer el universo es descubrir y reconocer esta necesidad. Por eso en estos sistemas lo gratuito, lo no necesario lógicamente, no puede existir. No cabe en ellos lo particular propiamente contingente. Y naturalmente no ha entrado aún en consideración la libertad y responsabilidad de la persona, en cuanto no determinada por la necesidad natural; y menos aún la posibilidad de una creatividad libre por parte de Dios.

\section{La sofistica, Sócrates y Platón}

El giro antroplógico que representan la solística y Sócrates parece un momento propicio para la valoración de lo único y singular, de lo gratuito y contingente, y de la libertad. Ahora se empieza a distinguir entre fysis y nomos, entre necesidad natural y convención social; en definitiva, entre la naturaleza y el hombre. Empieza a proclamarse el valor de la conciencia individual en tonos tan solemnes como los que se pueden oír en la Antígona de Sófocles; y de una manera mucho más cercana a los problemas de la vida cotidiana en muchas piezas de Euripides.

Pero uno no puede dejar de tener la impresión de que el hallazgo de lo que es personal y libre resulta de hecho tan sorprendente y tan nuevo, que no acaba de aceptarse. No me refiero, naturalmente, al que podríamos llamar concepto polfítco de la libertad, que quiere decir no estar sometido a ningún poder extrínseco, como serfa el caso de la esclavitud o de la dominación extranjera. Esta libertad sí que es valorada y proclamada, desde la elegías de Solón, pasando por Herodoto o "Los Persas" de Esquilo —en relación a la prototípica esclavitud persa-, hasta los discursos patrioteros de Tucídides. Me refiero a la apreciación de la propia libertad intrínseca de la persona, a su capacidad de autodeterminación. El espíritu de la tragedia clásica, o aquel pathos tan peculiar de Herodoto sobre la suerte de los hombres y la envidia de los dioses, muestran cómo el resurgir del sentido de libertad y autodeterminación del hombre chocaba con un sentido más profundo de necesidad y de fatalidad, impersonales y abrumadores. Los héroes trágicos o los hombres de Herodolo se creen libres, pero no lo son. De hecho están movidos por los hilos invisibles de una fatalidad, que expresa la ineluctable necesidad que rige al universo. En un sentido no muy diferente al de los filósofos, los trágicos enseñaban también que la verdad es la necesidad, aqui concebida como fatalidad, y que la ciencia verdadera es la sabidurla que consigue captar lo que ya está predeterminado necesariamente. Lo demás es sólo ilusión. 
Tal vez alguien diga que la tragedia, Herodoto y también Píndaro $\longrightarrow$ quien convendrla aludir como representante de una concepción dominada por el sentido de la necesidad cosmica - vienen a ser los últimos representantes de una concepción arcaica y hasta quizás pretendidamente arcaizante. El nuevo espiritu vendría representado por hombres como Protágoras, que afirmaba que "el hombre es la medida de todas las cosas;" o por el sofista Antifonte y el político Critias -y sus hijos espirituales, tan bien dibujados en los tipos platónicos de Calicles y Trasimaco-, que proclamaban sin rubor que el hombre decidido no ha de hacer ningún caso de leyes ni convencionalismos, y únicamente ha de hacer aquello que convenga a su interés. Hay en estos autores como un entusiasmo místico por el descubrimiento de la libertad, escrito en tonos que ya no se encontrarán hasta los tiempos de Nietzsche o de Gide.

Pareceria, pues, que al menos el pensamiento progresista e ilustrado del siglo IV ha descubierto al hombre como libertad. Pero pienso que esta afirmación tendria que matizarse mucho, porque parece que lo que de momento extasió al pensamiento ilustrado no fue tanto el descubrimiento de la libertad de la persona frente a la necesidad de la naturaleza, cuanto el descubrimiento de la libertad del individuo frente a los convencionalismos de la sociedad. O si se quiere, parece que se trata más del descubrimiento del carácter convencional -y en este sentido, no necesario- de las instituciones sociales, que del descubrimiento de la libertad de la persona como ser capaz de hacerse a sí mismo en relación con la naturaleza y con los otros hombres. Por eso parece que de momento sólo se consigue como una devaluación del nomos frente a la fysis, pero no se profundiza en la singularidad y peculiaridad de la fysis humana como centro de autodeterminación, en contraposición a la determinación del cosmos natural o fysis cosmológica. Algo de esto venía a decir $\mathrm{M}$. Pohlenz cuando distinguía entre "libertad política" y "libertad interior," y notaba que no se llegaba a una plena conciencia de la "libertad humana," sinlesis integrada de las dos, sino en la época helenística. 5

Quien verdaderamente se dispone a conquistar la libertad interior frente a todo determinismo natural, superando la antítesis simplista entre fysis y nomos, es Sócrates. Sócrates piensa que el hombre no se ha de dejar llevar ni por la pura convención social ni por una determinación de naturaleza prefijada y ciega. El hombre ha de autodeterminarse por el bien, descubierto y percibido como tal. Por eso prácticamente toda la actividad socrática, con su característico método dialogal, va dirigida al descubrimiento de lo que es bueno para el hombre. Lo específicamente humano, según S6crates, sería conformar la propia conducta a la percepción del bien. En este sentido, Sócrates sería el descubridor de la libertad como capacidad de escoger el bien. Con todo, parece que también esto se habría de matizar: parece que Sócrates se preocupó más del problema del descubrimiento y reconocimiento del bien -0 , como lo diría después Aristóteles, de la "definición" de los términos morales-, que de la misma cuestión de la libertad. Las conocidas tesis del intelectualismo ético -que nadie hace el mal a conciencia y que el mal no se hace por malicia sino por ignorancia o error-parecen abonar la 
idea de que para Sócrates el hombre, más que un ser libre, era un ser determinado al bien; sólo que equivocado en la apreciación del bien verdadero.

Seguramente nunca se acabará de averiguar si Platón fue realmente un continuador o un traidor de Sócrates. Seguramente no andariamos errados si sospecháramos que necesariamente había de ser ambas cosas a la vez. Lo que si podemos decir, respecto al tema de la liberlad que nos ocupa, es que Platón significa un retroceso.

Sus planteamientos venían dados en cierta manera por los de su maestro: si lo que convenia era descubrir el bien verdadero, se habla de suponer que éste era algo real, existente; y además algo identificable y, por tanto, determinado, fijo, permanente... y necesario. Es patente de dónde viene la afición platónica por la idea del bien: parecia el presupuesto necesario para dar estabilidad y coherencia a la ética socrática. Pero, según cómo, también era la negación de esta ética. Porque se vuelve a situar el bien en el reino de la fysis necesaria, de lo que es necesariamente, con necesidad a la vez lógica y ontológica. El sistema de Platón representa el máximo esfuerzo - grandioso y admirable, pero en definitiva frustrado- por reducir toda la realidad - incluidos hombres y sociedad - a una ley de necesidad. El principio de necesidad lógica, las ideas universales y necesarias, queda establecido como principio de necesidad ontológica: sólo las ideas, necesarias e inmutables, tienen verdadera realidad; sólo ellas "son" en el sentido pleno y fuerte de la palabra. Las "cosas" concretas, por ser contingentes y mudables, es decir, no necesarias, no "son" realmente. 6

Cediendo, pues, a la exigencia de necesidad, postulada desde unos prejuicios epistemológicos que se hablan impuesto desde los mismos origenes de la especulación helénica, - - , si $s$ quiere, intentando superar el impasse de Parménides, pero sin abandonar sus presupuestos-, Platón construye un duplicado necesario del mundo sensible y contigente, o bien, como diría él, declara que el mundo contingente no es más que un duplicado degradado del auténtico mundo necesario. Y entonces, el filosofo-rey que quiera hacer algo para poner un poco de orden en este mundo tan afectado por la mutalibilidad e inestabilidad, lo mejor que puede hacer es intentar imponerle aquella misma necesidad que habla descubierto en la contemplación del mundo de las ideas necesarias. O sea que, en un primer paso, la necesidad lógica se convierte en ontológica; pero, en un segundo paso, se quiere convertir la necesidad ontológica en necesidad ético-política

La idea del bien resulta ser, entonces, la necesidad total, en la que se estructuran y se engloban las necesidades parciales de las otras ideas: por referencia a aquella idea suprema, todo serd absolutamente inteligible, absolutamente bueno, absolutamente inmutable, absolutamente necesario. Estamos en un sistema en que todo parece girar en tormo a la idea del bien, y que por esto podria ser llamado un "mecanismo del bien." Y éste es prácticamente siempre el resultado de los sistemas que se presentan como finalistas, cuando ponen más énfasis en la atracción del bien final que en la libertad y responsabilidad con que se ha de tender a aquél. 
Aqui es donde aparecen las mayores dificulades e insuficiencias dentro del sistema platónico. Desde su determinismo epistemológico y ontológico, heredado de Parménides, Platón no puede explicar la contingencia del mundo material, y menos aún puede acabar de admitir una verdadera libertad humana, por más que se esfuerce. Es sabida la manera cómo intenta explicar la contingencia mundana en el Timeo: empieza distinguiendo lo que es eternamente y sin generación (es decir, el ser necesario, las ideas necesarias, intuidas como tales por la mente) y el ser objeto de generación (contigente) percibido por los sentidos y por la opinión. El ser necesario es por sí mismo autoexplicativo. El ser contigente, en cambio, que no es inteligible desde su propia necesidad, lo será desde la necesidad de su causa: "todo lo que llega a ser, llega a ser como efecto necesario de una causa" (28a). Asf es como introduce la figura del Demiurgo, causa necesaria - "modelador y padre" - del universo en devenir. Siguen muchas páginas, de imaginación brillante y agudamente sugestivas, que querrian explicar de qué manera el Demiurgo moldeará nuestro universo contigente. Platón no se cansa de sugerir que el Demiurgo lo hace todo lo mejor posible, procurando imitar en todo al modelo, al ser eterno autonecesario y autinteligible, "en la medida de lo posible." ¿Por qué, pues, de hecho, el mundo resultante es tan diferente e inferior a aquel modelo? Platón es consciente de que no acaba de explicar cómo de la necesidad perfecta puede salir la contigencia imperfecta. En un momento determinado llegará a excusarse diciendo: "es natural que nosotros, que somos seres tan sujetos al azar, hablemos también un poco al azar" (34c). Se trata de uno de aquellos incisos deliciosamente irónicos y sinceros, que encantan a todo lector sensible de Platón. Pero, finalmente, ya no podrá escabullirse de la dificultad. Evidenternente nunca concederá a sus contrincantes atomistas que el mundo sea sólo efecto del azar, o de la necesidad ciega. Pero habrá de conceder que tampoco es sólo efecto de la inteligencia o de la necesidad autointeligible. El mundo surge como "una mezcla de necesidad y de inteligencia" (48a). Ya quisiera el Demiurgo hacer el mundo lo más semejante posible al mundo de la necesidad luminosa de las ideas etemas y necesarias, pero parece que no se lo permiten la resistencia y la interferencia de la necesidad tenebrosa del caos y de la materia donde él intenta poner luz y orden. Los comentaristas destacan lo que hay de resonancia mitológica en esta concepción: estamos todavía al nivel de las antiguas cosmogonías de Hesíodo, cuando los dioses luchaban con las fuerzas del caos. El esfuerzo gigantesco del racionalismo griego en el que podríamos llamar su momento culminante - la madurez del pensamiento platónico- se declara vencido: no ha podido triunfar en el intento de explicarlo todo a partir de una autointeligibilidad necesaria, $y$ ha tenido que admitir la presencia, al menos, parcial - "mezclada" - de lo inexplicable, de lo irracional, es decir, de otra necesidad ciega y tenebrosa.

Es patente que en este sistema queda muy poco espacio para la libertad humana. Y no es sólo que Platón tuviera muy poca simpatla por quienes defendían las libertades políticas, dada su ascendencia y actitudes aristocráticas. Es que su ontologia apenas dejaba lugar a una antropologia de la libertad. Evidentemente, 
también aqul sintió las insuficiencias de su sistema y buscó una solución. El mito de la calda de las almas, en el Fedro, es un intento genial en este sentido. Pero veamos lo que ofrece: las almas están en su mejor estado cuando siguen fielmente -ciegamente- su órbita celeste. El ejercicio de la libertad es un accidente, una triste deficiencia de funestas consecuencias para las almas que caen en el mundo de la materia y de la contigencia. Desde aquí es desde donde se ha de considerar el alcance de las restricciones concretas a la libertad de los individuos -a menudo tan drásticas_ que Platón propone cuando da normas políticas en la República o en las Leyes. Platón no puede esperar mucho de la libertad humana, y es este sentimiento profundo el que impregna de pesimismo toda su obra. Suefla en otro mundo más auténtico, más "racional," por estar más necesariamente determinado al bien. Alll ya no tiene sentido hablar de libertad. Alll las almas estarlan necesariamente adheridas al bien, y punto. Pero en este degradado mundo nuestro, lo mejor que Platón puede desear es que un filosofo-rey, con los cuerpos coercitivos que convenga, nos persuada o nos fuerce hacia aquel bien, que ya no somos capaces de alcanzar por nosotros mismos. Y cuando ve que ni tan sólo así es posible, que al menos las leyes y las instituciones de la ciudad, con un sabio sistema de halagos, premios y amenazas, nos acerquen lo más posible al bien que, evidenternente, ya se entrevé como algo nunca plenamente asequible.

Siendo un sistema dominado por el principio de la necesidad, el platonismo no da lugar ni a la libertad, ni a la relación gratuita del amor, cosas absolutamente primarias en la concepción cristiana de la existencia. Quizás sorprenda a alguien lo que digo del amor, pero el amor en Platón, que tiene muy poco que ver con lo que habitualmente se llama "amor platónico," es sólo la atracción necesaria del bien. Una atracción que casi podriamos calificar de física o mecánica, y por eso tiene su principal analogado en la atracción sexual y se llama Eros, muy distinta de aquella otra forma de amor para la cual se quiere reservar el nombre de ágape, y que implica siempre verdadera libertad de aulodonación y verdadera gratuidad, que es todo lo contrario de la necesidad.

\section{Aristóteles: el ser necesario y los seres contingentes}

Como se sabe, Aristóteles modifico los planteamientos de Platón. Con todo, por lo que respecta a lo que ahora tratamos, se puede decir que sus posiciones son análogas, aunque formuladas más rigurosamente, dado su talante; y por eso seguramente son también más incisivas. Aristóteles también postulará que el único objeto de una verdadera ciencia es "lo universal," la "esencia," es decir, lo que es logicamente necesario; no el individuo particular, contigente y mudable. Igualmente dirá que el mélodo propio del conocimiento será el del descubrimiento de las relaciones necesarias, que él llama "causas." Desde entonces toda la ciencia occidental se ha ocupado sólo de esto: hallar relaciones necesarias entre sí, para llegar a nuevas formulaciones de relaciones necesarias, como a caballo sobre las primeras. 
Esto quiere decir que el individuo como al no puede ser objeto de la ciencia aristotólica. Es verdad que Aristóteles no niega, como lo hacía Platón, la realidad plena del existente concreto. Sin embargo, llevado por el mismo prejuicio de que sólo lo que es necesario puede ser objeto de conocimiento, declara que propiamente sólo podemos conocer de lo concreto lo que en él hay de universal: la esencia y sus propiedades esenciales. Lo demás es "accidental," y aunque lo podemos percibir, ni lo conocemos propiamente ni tiene interés para la ciencia

Es manifiesto que en un sistema así el primer principio de todo habrá de ser un principio de necesidad. Y es precisamente esto lo que dice Aristóteles en el conocido capítulo 7 del libro XI de la MetafLsica: "es algo que es por necesidad... que no puede ser de otra manera, sino que es absolutamente. De tal tipo de principio dependen el cielo y la naturaleza" (1072b). Fue a partir de este pasaje que resultó habitual en la escolástica hablar del "ser necesario." Sin embargo, habriamos de pensar que el primer principio de Aristóteles no sólo es necesario en el sentido que es lo que es por sí mismo, como por propia necesidad interna, sino que, no pudiendo ser de otra manera de como es, actúa siempre necesariamente. Y, por tanto, el cielo y la naturaleza que de él dependen son tan necesarios como él mismo, ya que son el efecto necesario de su acción. Quien pone un ser absolutamente necesario como principio de todo, pone de hecho un principio absolutamente necesitante: todo se sigue necesariamente de este principio necesario, todo queda englobado en la misma necesidad universal. En realidad el "ser necesario" de Aristóteles no puede ser otra cosa que el inmanente e intrínseco principio de necesidad del universo; o siguiendo la analogía del primer motor inmóvil, es como el centro universal de atracción y de cohesión de todos los movimientos necesarios, que por eso -como explica el filosofo minuciosamente- solo pueden ser movimientos circulares, ya que éstos son los movimientos que siempre permanecen iguales y vuelven siempre a lo mismo. El mundo de Aristóteles es tan necesario en la diversidad de sus movimientos y cambios como el mismo ser necesario o primer motor que lo sustenta. Si realmente queremos salir de aquella "prisión de las cadenas de la necesidad, "que decla Parménides, no basla poner únicamente un principio de necesidad, si no se pone al mismo tiempo un principio de no-necesidad, de gratuidad, de libertad. $Y$ es curioso constatar que el mismo Aristóteles lo habla intuido. Pero parece que no llegó a sacar las consecuencias, porque en su deseo de rigurosa necesidad lógica sólo podía llegar a una igualmente rigurosa necesidad ontológica.

En efecto, un poco antes de lo que comentábamos, Aristóteles dice contra los platónicos: "de nada serviría poner sustanciás eternas, como hacen los partidarios de las ideas, si no hay asimismo algún principio que pueda originar los cambios" (1071b). Este es el problema de los sistemas que ponen al principo lo absolutamente necesario, lo absolutamente eterno, lo absolutamente inmutable... Lo necesario en cuanto tal no puede ser causa de lo contingente; ni lo etemo de lo temporal; ni lo inmutable de lo mudable... Aristóteles, sin embargo, pensabs superar a los platónicos por el hecho de que él no ponía sustancias etemas y 
necesarias, sino un motor etemo y necesario, que - como subraya claramentees por esto mismo pura y total energeia o actividad. Bien; supera a los platónicos al poner un principio de absoluta necesidad dinámica en lugar de un principio de necesidad estática, como quizás eran las ideas. (Aunque yo me inclino a creer que aquí Aristóteles, como en tantos otros lugares, hace una mala jugada a Platón, ya que la idea platónica del bien era al menos tan dinámica como el motor inmóvil). Pero ni el uno ni el otro serán realmente capaces de deshacerse de las "cadenas de la necesidad."

Es que Aristóteles, en definitiva, fiel a la tradición racionalista que sólo acepta como inteligible lo que se puede mostrar como necesario, trata de explicar la necesidad del cosmos, del orden del universo. Se siente fascinado por el movimiento ordenado, regular y necesario de los astros, del que resultan los cambios de las estaciones y el ritmo vegetativo, y que suministra el punto de referencia para la medida del tiempo. Y todavfa lascina más a Arisbóteles la posibilidad de explicar la multiplicidad aparentemente incoherente o cabtica de los sucesos por sus causas necesarias, es decir, reducir lo que parece eventualidad a una necesidad. Así es como se llegará a un "ser necesario," principio o fundamento de lodas las necesidades parciales, que se revelan en la nauraleza.

Se puede decir que el acceso a Dios por esta vía de la necesidad cosmológicoontológica, profundizada y reelaborada por San Agustín (desde un aire más platónico y epistemológico) y por Santo Tomás (más fiel a Aristóteles en el planteamiento ontológico) ha marcado de manera predominante al teísmo occidental hasta nuestros días, a pesar de que lleva a una imagen de Dios, en el fondo, diffeilmente compatible con la imagen brblica y cristiana de Dios, que es la de un Dios de gratuidad, liberlad y amor.

Por la vía aristotélica, se llega a un Dios concebido como ser necesario, absoluto, autosuficiente, inmutable, impasible... El problema, entonces, consiste en concebir cómo un Dios tan absoluto y necesario puede tener algo que ver con lo que es contingente, mudable y finito. Por eso Aristóteles ha de suponer que su Dios-motor es una pura energeia, absolutamente autosuficiente y feliz en sí mismo, que en realidad sólo tiene conciencia de sí mismo y no de las cosas mudables, que le afectarian de mutabilidad; que lo mueve todo, no mediante cualquier tipo de esfuerzo o de acción de sf mismo dirigida hacia algún otro -cosa que le haría depender del otro-, sino de una manera en la que él mismo queda inafectado y como pasivo, a la manera como una realidad amable atrae al amante 0 un objeto inteligible mueve la inteligencia sin ser él mismo afectado en su ser ( $M i$ XI 7$)$.

Las hipolecas de esta concepción cuasi-mecanicista las he explicado en otro lugar: ${ }^{7}$ el tipo de Dios en que piensa Aristóteles se manifesta como de pasada en la Etica Eudemia, cuando habla de si el hombre necesita tener amigos para ser feliz. Dice:

El que es autosuficiente no necesita ni de los servicios de los demás ni del 
gozo de su afecto, ni de su compañía, sino que es muy capaz de vivir solo. Esto queda muy claro si miramos lo que pasa con Dios: es obvio que Dios, que no tiene necesidad de nada, tampoco necesitará amigos, ni nada que le afecte de modo que lo domine.

Aristóteles sigue sacando consecuencias pertinentes:

Asi, pues, el hombre más feliz será el que menos necesite de amigos, excepto en las cosas en que le sea imposible conseguir la autosuficiencia. Por tanto, quien ha llegado a la vida perfecta, conviene que tenga los menos amigos posibles, cada vez menos, y que no se preocupe de tenerlos (Eth. Eud. VI $1244 \mathrm{~b}$ ss.).

Parece imposible que todo un Aristóteles pueda admitir esta monstruosa conclusión. Pero ésta es la lógica del principio de autonecesidad y de autosuficiencia. Si Dios es el ser absolutamente autonecesario por sí mismo, de ninguna manera puede depender de otro. Parece que no puede amar nada fuera de sí mismo, porque si amara algo fuera de sí, ya no sería aulosuficiente, sino que dependería del otro.

Quizás por esta razón los escritos de Aristóteles son en realidad tan poco "religiosos," a pesar de su insistencia en atribuir el calificativo de divino al primer principio o motor. Su principio sirve más para dar razón de los movimientos etemos de los cielos astronómicos, que para descubrir el posible sentido de las contingencias de la existencia humana aquí en la tierra, que, en definitiva, es lo que con más propiedad pertenece a la religión. En este sentido, Aristóteles es el primer deísta, y tiene toda la frialdad, brillante pero inhumana, de todos los deŕsmos: deslumbran porque parecen explicarlo todo, hasta que se descubre que no sirven para nada, que son puras construcciones teóricas que no tienen aplicación a la realidad, tal como el hombre la vive y la experimenta.

El estoicismo y el epicureísmo se puede decir que son dos formas de reacción lógica, cada una a su manera, ante la ineluctable necesidad en que el mundo se presenta al hombre antiguo. El estoico dice que se ha de hacer de la necesidad virtud. El epicúreo piensa que lo mejor será ignorarla y vivir la propia vida en la medida en que se pueda de la mejor nanera posible. Ambas corrientes alcanzaron formas de una grandeza y nobleza muy superiores a lo que pensariamos, si sólo se hiciera caso de los tópicos estereolipados. Con todo, en el fondo, son corrientes socavadas por la resignación y la desesperación. Claro que el hombre quiere reaccionar, pero se sabe vencido de antemano. El hombre nada puede ante la fatal necesidad de un mundo que eternamente vuelve sobre si.

Podríamos hablar aún del neoplatonismo, como de un esfuerzo sistemático particularmente sutil para superar la irreductibilidad entre el primer principio, concebido como Uno necesario, y la realidad de lo contingente plural y mudable. La ingeniosa interposición de hipostasis intermediarias lo único que hace es disimular la radical incompatibilidad que se da entre los extremos, e incluso entre cada una de las hipostasis y la que le sigue inmediatamente. 
Pero nuestro proósito no es revisar todo lo que se ha dicho sobre el primer principio, sino más bien mostrar cómo el proceso de identificación de Dios como principio de necesidad cosmológica y ontológica, tal como fue intentado por los griegos, comporta muy serias dificultades en si y parece llevar a una imagen de Dios y de su relación con el mundo, realmente incompatible con la tradición de la revelación judeo-cristiana.

\section{Necesidad, naturaleza y libertad}

El tema de la necesidad en la filosofia griega es realmente inagotable. No he hecho más que sugerir algunas pistas de reflexión y algunos enfoques indudablemente parciales. Permítaseme subrayar ahora, como conclusión, algunos aspectos que me resultan más dignos de atención.

En primer lugar, la identificación -fáctica e implícila- de "necesidad" e "inteligibilidad," que es como la piedra fundamental del racionalismo. Sólo se admite lo que puede ser demostrado con necesidad lógica. Pero esta necesidad lógica tiende a convertirse en necesidad ontológica. (Pasarán siglos hasta que venga Kant a proponer que puede tratarse sólo de una necesidad impuesta por las formas a priori de nuestro conocimiento). Inicialmente se ve la necesidad como una categoría de la realidad. "Es" lo que está determinado necesariamente, y conocer la realidad es conocer sus determinaciones necesarias: su esencia intrinseca y las causas de su devenir. Esto supone diversas formas de determinismo cósmico: desde el monismo eleático hasta los pseudo-pluralismos de Empédocles, Demócrito o Anaxágoras (donde la pluralidad está realmente vinculada y unificada por principios de necesidad); al dualismo de Platón (donde el mundo real es el mundo de las ideas necesarias, y lo demás es sólo una apariencia realmente inexplicable); y a la pancausalidad aristotélica, (donde todo se explica por un complejísimo juego de causas mutuamente coordinadas y subordinadas, dependiendo de una primera causa o primer motor, causa en verdad necesaria y ciega, que no puede ser más que lo que es, ni puede mover de otra manera que por su poder de atracción intrínseco y necesario, y que implica que todo lo demás es igualmente necesario en dependencia de aquella causa). Quizás alguien reprochará, en contra de lo que digo, el carácter indudablemente teleológico de la filosofía natural aristotélica, y su valoración de la causalidad linal como la suprema de las causas. Si, pero se trata de una finalidad igualmente necesaria. La fysis tiende necesariamente hacia su telos. No hay nada verdaderamente contingente o eventual: nosotros llamamos fortuita o contingente a la realidad, cuando somos incapaces de averiguar y controlar sus causas, demasiado complejas o escondidas.

En segundo lugar, en un mundo asi concebido como un todo de necesidad cósmica, no se ve cómo pueda darse una verdadera libertad humana. El mundo griego parece que sólo llega a concebir la libertad como ausencia de coacción extrínseca, no como verdadera capacidad de autodeterminación. Porque la libertad en este sentido implica una concepción de la persona como contrapuesta a la naturaleza, en la cual el hombre es un ser que no está sólo determinado por las leyes de la 
naturaleza, sino que es verdaderamente autocreador de sí mismo y de su destino, más allá de un puro determinismo natural. Esta concepción del hombre como ser que trasciende la naturaleza, se puede vislumbrar en los mejores momentos del pensamiento griego. Pero la idea del determinismo cósmico hace que esta intuición no se acabe de desartollar. M. Pohlenz, en su capítulo sobre "La libertad interior" en la época clásica, recopila algunos textos -principalmente fragmentos de Eurípides-, donde parece que hay una cierta vivencia experiencial de libertad interior. Pero son textos de interpretación muy ambigua. Cuando Medea dice (v. 1078): "sé bien el gran mal que estoy a punto de cometer, pero por encima de la razón me impulsa la pasión," ¿podernos afirmar que se expresa aquif una verdadera conciencia de libertad, o más bien hemos de decir que se expresa en la pasión la necesidad ineluctable de la naturaleza? Lo mismo se podrla decir del fragmento 840: "Tengo suficiente conocimiento, pero me arrastra la fuerza de mi naturaleza." Al menos hay que decir que la interpretación que Pohlenz da a estos pasajes parece abierta a muchas reservas.

Como ya he insinuado, diria que Sócrates es quien llega más cerca de una verdadera libertad interior, con su concepción del hombre como ser que ha de descubrir por sí mismo la naturaleza del bien, para ponerlo en práctica Nadie que haya leído la Apologí dudará que alli suena la voz auténtica del hombre libre. Pero Platón vuelve a dificultar la antropologia, con su voluntad de sibuar al hombre y su bien dentro de una gran ontología de necesidad. El sistema platónico es sólo el sistema de omnideterminismo del bien, más ontológico que propiamente intelectual. En algunos momentos de la ética aristotélica parece que se vuelve a encontrar el aire de la libertad intencional, como la concebía Sócrates. Pero realmente este tema no se desarrolla por sí mismo. Aristóteles se interesa más por lo que podriamos llamar "mecánica psicológica" del actuar humano, concebida otra vez según esquemas de necesidad, que conducen a su compleja teoría de los hábitos y las virtudes.

Finalmente, me atrevere a decir dos palabras sobre un tema que ya he apuntado al principio y que fue el que me movió a las reflexiones que he expuesto. El pensamiento filosófico griego, con su constante manía de fundamentar la racionalidad y la inteligibilidad en la necesidad, ıpuede calilicarse, como quería W. Jaeger, de pensamiento teológico y religioso, que sustituye la acción gratuita y caprichosa de los dioses míticos por la omnipresencia de un dios filosófico; 0 bien, como decía K. Reinhardt a propósito de Parménides, es un pensamiento esencialmente secular y arreligioso, "que no siente otra fuerza que la de la lógica y que permanece indiferente ante Dios y el sentimiento"?9 Es evidente que la respuesta depende en buena parte de lo que se entienda por "religioso" y por "secular." Como es también evidente que K. Reinhardt, siguiendo una línea muy propia del protestantismo liberal alemán, supone que la religión tiene mucho que ver con el "sentimiento" y muy poco con la "razón."

Por mi parte, sólo quisiera sugerir que la cuestión se podría enfocar de otra manera. En una concepción del universo unitario y necesario, uno puede sentirse 
inclinado a atribuir cardeter divino al primer principio de necesidad que lo une y determina todo, tal como hicieron los pensadores griegos desde Parménides a Aristoteles. Lo que parece diffcil de admitir es que, a pesar de este carácter divino que se atribuye al universo, se pueda seguir hablando aún de "religión." Porque parece que hablar de religión quiere decir hablar de alguna manera de una responsabilidad, de una posibilidad de relación libre y personal de los hombres hacia la divinidad, que implicaría correlativamente una posibilidad de relación semejantemente libre y al menos cuasi-personal de la divinidad para con los hombres. Reconozco que al hablar así quizás me dejo influir demasiado por lo que son de hecho las formas religiosas del judeo-cristianismo, tan determinantes de nuestra cultura occidental. Pero pienso que si se pone un principio de necesidad absoluta - lógica y ontológica - ya no hay lugar para lo que habitualmente se entiende por religión, sino solamente para una forma de aceptación de la necesidad ontológica de la que uno puede sentirse parte, y que quizás pueda asumir un matiz religioso bajo la forma de resignación más o menos valiente o desesperada, como preconizaba - muy coherentemente- el estoicismo. En este sentido, yo darfa la razón a K. Reinhardt contra W. Jaeger. el pensamiento griego, en cuanto pone como último principio de todo un principio de necesidad, aunque califique a este principio como divino, es un pensamiento fundamentalmente arreligioso y secularizante.

En cambio, no me sentiria tan identificado con K. Reinhardt cuando parece contraponer filosofía y lógica de necesidad, por un lado, y religión y sentimiento, por otro. Pienso que el lugar donde propiamente se inserta la religión no es el del sentimiento, sino el de la libertad y responsabilidad del hombre ante sf mismo, ante el mundo y frente al sentido que puede tener su existencia. Bajo este punto de vista, no veo que Parménides y Jenofánes puedan Lamarse pensadores religiosos; si, en cambio, Sócrates. Mientras que en Platón y Aristóteles habria una cierta ambigiledad, en cuanto que un genuino sentido religioso de responsabilidad y libertad, heredado de Sócrates, se envuelve y quizás prácticamente se ahoga dento de una ontología en el fondo parmenidiana

Dicho de otra manera, la religión es la actitud del hombre que asume su sibuación en devenir y se siente responsable de ella ante una instancia, que, siendo absoluta, regula el futuro, no absolutizándolo o necesitándolo como una necesidad ontológica y cuasi-mecánica, sino como un proyecto que ha de ser realizado por hombres libres y responsables.Recogiendo un pensamiento de Bergson, sólo hay religion donde hay un Dios libre y responsable, aulor de hombres libres y responsables; es decir, donde hay una historia y un futuro, del cual Dios permanece verdaderamente Seflor, pero no por imposición de necesidad ontológica, sino como una propuesta a realizar por parte del hombre. La filosofía griega, que nunca consiguió valorar el devenir sino como una forma degradada del ser, no podía lograr valorar la religión como lugar donde el hombre asume su futuro frente al absoluto. 
Vendría a ser lo que dice $\mathrm{N}$. Berdiaev con unas palabras que me parecen precisas: "sólo hay historia si se puede hablar, por una parte, de un fin o valor absoluto del mundo y, por otra, de una verdadera libertad del hombre para aceptar o rechazar este fin. Sólo hay historia si se dan a la vez Dios como Setior de la historia y el hombre como libre ejecutor de ésta. Sin el primero, los sucesos quedan reducidos a un juego gratuito, irrelevante y cático; sin el segundo no puede haber más que la ciega necesidad de un destino fatal."10

\section{$\downarrow 4$}

Estas páginas no pueden tener la pretensión de haber agotado un tema sumamente rico y complejo. Sólo he querido remarcar algunos puntos característicos del pensamiento griego, que lo diferencian notablemente de la concepción cristiana del mundo, del hombre y de Dios. Es evidente que, al adoptar el universo mental de la filosofía helénico-aristotélica, los té́logos cristianos de la edad media no podían adoptar su principio de fatalidad y de necesidad. Así Santo Tomás, por fidelidad a la Biblia y a la genuina tradición cristiana, se convierte en sutil corrector de Aristóteles aun alli donde profesa seguirlo como su "filosofo." Queda, con todo, como pretensión básica de la teología escolástica la de explicar las relaciones entre el mundo y Dios, según el modelo de rationes necessariae, así como la tendencia a considerar la palabra de Dios en su revelación más como una palabra que informa sobre estas rationes que como una palabra que interpela al hombre a realizar, en libertad y responsabilidad ante Dios, el sentido de la historia. La comprensión de la misma palabra de Dios como logos necesario hace que casi se pierda la sensibilidad para comprender la palabra de Dios como promesa y como don a realizar, dentro de un marco de la historia en el cual todo es gratuita e innecesaria donación de Dios y todo queda como libre y responsable realización del hombre. Es esta dimensión, poco atendida por la teología clásica, la que ha sido redescubierta y potenciada por la teología de la liberación. Esta me parece ser la mayor aportación de fondo, la auténtica novedad de esta corriente teologica. Ella ha hecho explotar, por insuficientes, los moldes demasiado estrechos que, provenientes del helenismo, todavía aprisionaban a la teología. Y lo ha hecho, no, como pretenden algunos, dejándose arrastrar por ideologias políticas a la moda, sino oyendo el clamor de la inmensa masa de pobres y desposef́dos de este mundo y preguntándose qué sentido puede querer dar Dios a la triste historia de este mundo, y qué hemos de hacer nosotros, en libertad y responsabilidad con Dios y ante Dios, para que la historia no sea un absurdo sin sentido. Los pobres no nos dejan admitir que Dios sea un principio de fatal necesidad, sino una interpelación al sentido en libertad. 


\section{Noras}

1. Editorial Sal Terrae, Santander, 1982. Desde uns perspectiva distinta, que no debiera ser pasada por alto por los téblogos de la liberación, E. Jíngel ha cuestionado tambien la idea clásica del "Dios necesario" en Dias como misterio del mundo, Salamanca: Sigueme, 1984, pág. 32 su. En el ímbito latinoarnericano vase $E$ Dias de las pobres, de Victorio Araya, San Jose de Coste Rica: DEI, 1983 (con copioss bibliograffe sobre el terna). Varios, La lucha de las dioses, ibid., 1980.

2. Die Theologie der frithen griechischen Denker, Stuttgart, 1953. Traducción castellane La teología de las primeras filosofos griegos, Mérico: FCE, 1952. Reimpresion, 1977.

3. Podrlan representar esta corriente FM. Comford, From religion to Philasophy, Londres, 1912. W. Nestle, Historia del espóritu griego, Barcelona: Ariel, 1961.

4. E. R. Dodds, Las griegos y lo irracional, Madrid: Rev. de Occidente, 1960.

5. Griechische Freiheit, Heidelberg, 1955, caps. 3 y 4.

6. La posturs del hombre ante el bien según Platón fue objeso de mi estudio: Génesis y evolución de la ética platónica, Madrid: Gredos, 1970.

7. Vease en la obra citada, La justicia que brora de la fe, cap. 3. La obre básica sobre la cuestion es la de J. Chevalier, La notion du Necessaire chez Aristote el ser prddecesseress, Paris, 1915.

8. Griechische Freiheir, capt 3.

9. W. Jaeger, o.c. 93, polemizando con K. Reinhardt, Parmenides und die Geschichte der Pihilasphie, Bonn, 1916, pág. 256.

10. N. Berdiaev, El sentida de la historia, Barcelons, 1996, pág. 47. 